
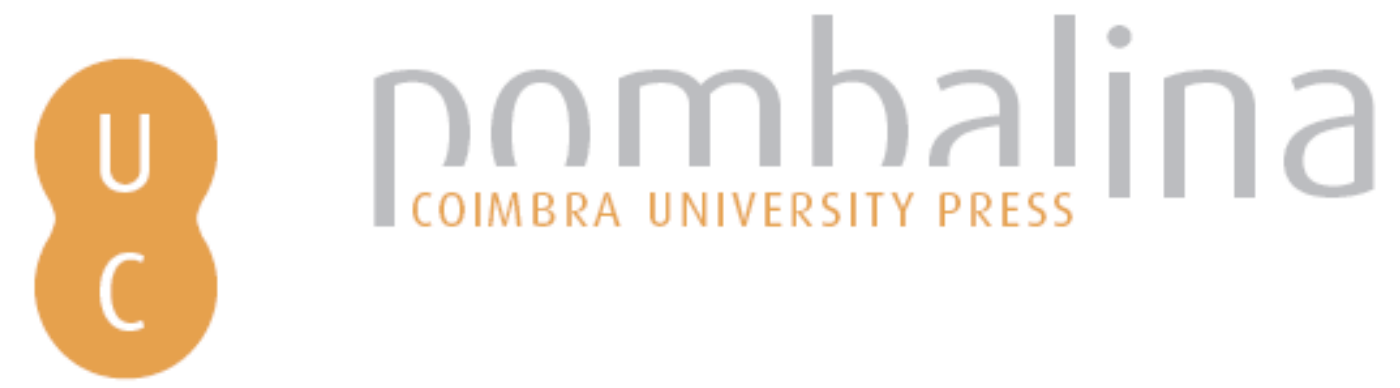

\title{
Subsbsidiariedade e critérios de senso comum na reabilitação inclusiva: necessidade de avaliação em saúde mental
}

Autor(es): $\quad$ Gameiro, Aires

Publicado por: Imprensa da Universidade de Coimbra

URL

persistente: URI:http://hdl.handle.net/10316.2/35965

DOI: $\quad$ DOI:http://dx.doi.org/10.14195/978-989-26-0852-5_12

Accessed : $\quad$ 26-Apr-2023 16:03:49

A navegação consulta e descarregamento dos títulos inseridos nas Bibliotecas Digitais UC Digitalis, UC Pombalina e UC Impactum, pressupõem a aceitação plena e sem reservas dos Termos e Condições de Uso destas Bibliotecas Digitais, disponíveis em https://digitalis.uc.pt/pt-pt/termos.

Conforme exposto nos referidos Termos e Condições de Uso, o descarregamento de títulos de acesso restrito requer uma licença válida de autorização devendo o utilizador aceder ao(s) documento(s) a partir de um endereço de IP da instituição detentora da supramencionada licença.

Ao utilizador é apenas permitido o descarregamento para uso pessoal, pelo que o emprego do(s) título(s) descarregado(s) para outro fim, designadamente comercial, carece de autorização do respetivo autor ou editor da obra.

Na medida em que todas as obras da UC Digitalis se encontram protegidas pelo Código do Direito de Autor e Direitos Conexos e demais legislação aplicável, toda a cópia, parcial ou total, deste documento, nos casos em que é legalmente admitida, deverá conter ou fazer-se acompanhar por este aviso.

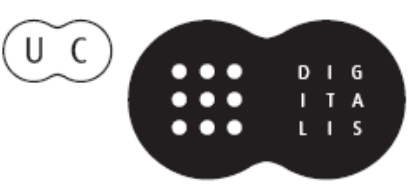



Aires Gameiro ${ }^{1}$

\section{SUBSIDIARIEDADE E CRITÉRIOS DE SENSO COMUM NA REABILITAÇÃO I NCLUSIVA. NECESSIDADE D E AVALIAÇ̃̃O EM SAÚDE MENTAL ${ }^{2}$}

Nota: Dedico esta minha apresentação às famílias com pessoas com limitações graves de autonomia as quais apesar de muita procura e de muitas promessas políticas não encontram resposta para reduzir a suas angústias. Falta investigação sobre a realidade das necessidades de famílias e pessoas dependentes em saúde mental, a grande procura de apoios ("subsídios") e a falta de resposta de meios adequados.

\footnotetext{
${ }^{1}$ Aires GAMEIRO é membro da Província Portuguesa da Ordem Hospitaleira de S. João de Deus em cujas instituições de psiquiatria tem trabalhado como psicólogo e em funções de director dos seus centros, da revista Hospitalidade e membro de diversos conselhos e comissões. Foi docente da UCP, do ISCTE e de outras escolas superiores. É doutorado em Pastoral da Saúde e Membro Investigador do IPCDVS da FPCE-UC. Colabora com CEIS20, UC; com o Dicionário Histórico das Ordens em Portugal (no prelo) e com o Congresso 2010 do mesmo nome. Tem tido actividades de formação nos centros da Ordem e fora, nas áreas da saúde mental, psicologia, alcoologia história da assistência, pastoral da saúde, migrações em mais de vinte países tendo participado em encontros e visitas de estudo em cerca de cinquenta. É autor de numerosos livros e artigos técnicos dessas áreas. Dos livros destacamos: Manual de Saúde Mental; Emigrantes (1984); Revolução e libertação: aspectos psicológicos e sociológicos da revolução [25de Abril] (1999); Evangelização e mártires do Japão e Coreia (1999); Novos horizontes da viuvez (1988); Tempo e originalidade assistencial de S. João de Deus (1997); Hábitos de consumo de bebidas alcoólicas 1995, 1991, 1997 (1999); Lusofonia e Identidade na Diáspora (2000); Alcoolismo nos Açores e na Madeira. Padrões de Consumo em 1999 e 2000. Linhas de Prevenção (2000); Timor, uma interpretação (no prelo); Casa de Saúde de S. Miguel. Ordem Hospitaleira de S. João de Deus. Antecedentes, Fundação e Desenvolvimentos, (1928-2008), (prelo). Rua de S. João de Deus 6 - 2495-456 Fátima. E-mail: aires.gameiro@isjd.pt

2 Comunicação no workshop: "Saúde Mental: Reduzir Dependência, Promover Autonomia". Aires GAMEIRO, Manuel Viegas ABREU, Margarida CORDO e Mónica FÉLIX, integrado no II CONGRESSO NACIONAL DE REABILITAÇÃO E INCLUSÃO NA SAÚDE MENTAL promovido pelo IPCDVS-UC/FCT com a colaboração da Associação ReCriar Caminhos, Coimbra, 12-14.10.09.
} 
Os discursos e os dados que aparecem são mais centrados nos profissionais que nos incapacitados e nas famílias com familiares dependentes, sem recursos e sem respostas apesar das muitas cunhas. Os textos do "aparelho erudito" e legal são muito distantes das pessoas e das suas aflições. São análises abrangentes com muitas variáveis e categorias técnicas mas de reduzida praticabilidade. A pessoa incapacitada e familiares sentem-se perdidos no "labirinto" que pretende ser uma construção exaustiva mas fica longe deles. Por vezes o número dos intervenientes e dos núcleos das redes parece ser superior aos casos a que conseguem dar resposta... A preocupação burocrática pelos processos é tanta que os serviços não chegam a muitos destinatários.

\section{Observações introdutórias}

Começo por distinguir os grupos de doentes incluídos na exposição e os que não são objectivo dela.

Não se incluem:

1. Doentes mentais agudos em crise e sub-agudos que vão sendo tratados nos hospitais gerais.

2. Doentes mentais sub-agudos, com sintomas de agressividade para os outros ou para si mesmos, devido a condição permanente ou a consumos tóxicos de álcool ou droga. Estes precisam de respostas à parte que tardam em chegar. Incluem-se na reabilitação para serem inseridos em ocupações produtivas mas raramente no mercado do emprego.

3. Doente dependentes com incapacitações totais ou quase totais e sem perigosidade.

É para estes que mais falham as respostas adequadas e desestigmatizadas de reabilitação e inclusão.

Incluem-se:

4. Doentes dependentes com menos de 50 anos com incapacitações variáveis, de ligeiras a médias, sem perigosidade. A maior parte dos 
discursos teóricos de empowerment e recovery têm por alvo este grupo.

5. E os doentes de mais de 50-60 anos para os quais a reabilitação se destina a desenvolver ou preservar alguma autonomia social. Estas idades são pouco compatíveis com ocupações formais. Estão incluídos na nossa comunicação para cuidados continuados, reabilitação e inclusão mas não como alvo de respostas de cuidados estigmatizados e segregados.

6. Incluem-se também as pessoas mais dependentes e incapacitadas adultas, idosas, com limitações, com ou sem rótulos de saúde mental. Precisam de cuidados continuados, reabilitação e inclusão em residências normalizadas e não em centros ocupacionais discriminados e estigmatizados com rótulos sócio-culturais psiquiátricos só para eles. Só os doentes com perigosidade grave, a avaliar caso a caso, precisam de respostas à parte.

Consideremos de maneira realista a situação presente:

1. Os cuidados continuados/reabilitação para pessoas com maior dependência, física ou psíquica são indispensáveis, exigentes e caros, para terem qualidade. Refiro-me a residências ou lares pequenos e médios com grande nível de normalização mesmo quando em módulos familiares.

2. Apesar de todos os discursos A MAIOR PARTE dos dependentes graves continuam a ser assistidos, mal ou bem, em lares de idosos vulgares e nas suas casas. E frequentemente sem apoios ou subsídios sócio-económicos adequados.

3. E não apenas os necessitados de cuidados continuados mas alguns necessitados de cuidados paliativos também são assistidos, mal ou bem, em lares e nas famílias. Todos temos experiência de casos de familiares e conhecidos. Ainda recentemente um familiar meu foi enviado com doença terminal para um lar vulgar onde faleceu passados meses. 
4. Além disso sabe-se que os lares são insuficientes e estão superlotados por falta de respostas adequadas e suficientes. São muito procurados com a mediação de muitas cunhas de profissionais e de familiares. E mesmo assim não chegam para responder à procura e pressão.

5. Muitos de nós, profissionais, lidamos com frequência com pedidos de familiares em stress e esgotamento que já bateram a dezenas de portas e batem também à nossa para ver se conseguem o impossível, um lugar em qualquer "refúgio".

6. Os próprios profissionais do SNS também se prestam a meter cunhas para familiares e amigos junto do sector social, ao mesmo tempo que a cada passo criticam as suas instituições por algumas deficiências que em parte são devidas à falta de equidade nos recursos públicos.

\section{Desinstitucionalizar para onde?}

7. Torna-se paradoxal que a desinstitucionalização psiquiátrica esteja a concorrer para perpetuar instituições psiquiátricas criticadas pelo sector público e para superlotar lares (às vezes sem condições por falta de capacidade económica dos utentes) e a sobrecarregar as famílias com problemas (cf. o Lar fechado de Arrouquelas, DN, 03.08.09 e Expresso, Mirante, 06, 13 e 15.08.09).

8. Temos ainda a pobreza como factor agravante. Uma percentagem de doentes mentais, mal ou nunca estudada de forma metódica, está incluída no escalão dos mais pobres do país. Para muitas famílias a única solução para a sua pobreza é o internamento, com ou sem reabilitação, em lares com ou sem condições ideais 3 . Quem o consegue mesmo que seja num asilo psiquiátrico recebe a sorte grande.

3 As estatísticas de pobreza e as de miséria confirmam que uma percentagem de 10 a $20 \%$ não dispõe de meios de sobrevivência. Desde os séculos XVIII, pelos doentes do hospital de S. José, pelos doentes mentais dos hospitais de Rilhafoles e de Conde Ferreira, da assistência dos doentes mentais em Ponta Delgada nos Açores; os problemas dos indi- 
9. E a domicílio com que apoios e subsídios são assistidos muitos dos dependentes? Mais por falta de respostas adequadas do que de abundância de discursos optimistas, muitos familiares têm que se desempregar para assistir os seus familiares 4 . Apesar de as instituições do sector social terem capacidade de resposta nesta área, um certo bloqueamento burocrático impede o seu funcionamento.

\section{Terminologia}

Convém atender e distinguir termos e conceitos. O uso da psico-linguística é crucial em reabilitação. Como dizia um psiquiatra: as intervenções psico-sociais holísticas têm de deixar de ser "puro e duro" tratamento médico para envolver as famílias e grupos de auto-ajuda. Se queremos reabilitar não faz sentido enfatizar o termo doente. Os termos reabilitando, formando, estagiário, apoiado teriam muito mais sentido. A tendência iatrogénica e psiquiatrizante preferem os termos mais pesados de doentes mentais, tratamentos.

Se privilegiarmos os termos "doente" provocamos uma dissonância na mente do reabilitando sobre a sua identidade: sou doente ou candidato à autonomia e independência?

Só reabilitação técnica ou apoios e subsídios para inclusão? A grande maioria dos institucionalizados, pela idade e pelas grandes limitações, entre elas a pobreza estrema, mais que reabilitação precisam de apoios e subsídios de subsistência a vários níveis para ascenderem a algum tipo de autonomia. A inclusão requer recursos humanos, recursos institucionais, mas por vezes ainda mais subsídios pessoais e familiares de subsistência

gentes vieram sempre "atrapalhar" os planos de tratamento dos autênticos doentes mentais (cf Aires GAMEIRO, Aspectos das políticas sócio-psiquiátricas no dobrar do século XIX-XX e as Ordens Hospitaleiras XVIII, Colóquio de História Militar: Politica Diplomática, Militar e Social do Reinado de D. Carlos no Centenário da sua morte, 03-06 Nov.08 pp.813-835; e Aires GAMeIro, Casa de Saúde de S. Miguel da Ordem Hospitaleira de S. João de Deus. Antecedentes, Fundação e Desenvolvimentos, (1928-2008), (prelo).

${ }^{4}$ Segundo o INE os Familiares que se desempregaram para cuidar de crianças, incapacitados e idosos subiram para 59 mil (cf. c. Almeida Pereira in DN Bolsa. 1.09.09). 
para fazer face à pobreza. Enquanto não os conseguirem ocupam o lugar na psiquiatria.

É fundamental perguntar: quem treina e forma para a inclusão na vida normalizada?

Não faz muito sentido treinar competências para a inclusão na vida normalizada com pessoal da saúde. Os profissionais da saúde deveriam ficar o mais distante possível dos treinandos, para não induzirem iatrogenia e dependência. Estariam disponíveis em regime de SOS. O treinando precisa de mudar a mente de que não é um objecto de cuidados mas um sujeito a cuidar de si.

O pessoal de saúde mental trata o lado doente. O pessoal da inclusão na vida normalizada treina as potencialidades positivas para a inclusão colocando o treinando ou estagiário no centro como sujeito a auto-incluir-se. A reabilitação precisa de recursos humanos de áreas de fora da saúde para desenvolver o que há de saudável na pessoa.

A inclusão requer recursos humanos da área social, ocupacional, comunitária e familiar e menos da área da saúde mental. Requer um "gestor" da pessoa em processo de inclusão. Os incapacitados e os seus familiares perdem-se no labirinto da rede criada para o ajudar. Precisam de uma pessoa de referência que seja sempre a mesma e faça de acompanhante e guia de viagem pelas áreas "labirínticas" de inserção.

\section{Alguns princípios operativos}

Há princípios que geram inclusão em contraste com outros que geram exclusão. Um dos primeiros é o da subsidiariedade. Subsidiar consiste em apoiar alguém com meios quando esse alguém não dispõe deles para se bastar sozinho nalguma área da sua vida. Não consiste em dar meios que o sujeito já tem ou não precisa. O subsídio ou apoio vicariante faz as vezes da pessoa em que ela carece de ser ajudada ou substituída. É subsídio para uma incapacidade e não substituição em tudo.

Se o sujeito é capaz e autónomo nalguma área não precisa de acções vicariantes para o ajudar mas pode precisar de subsídios noutra área para fazer face, por exemplo, à sua pobreza. 


\section{Áreas de subsidiariedade vicariante}

A distinção de áreas e selectividade dos subsídios é fundamental para não cair no erro de os dar em áreas deslocadas ou áreas já cobertas e deixar outras a descoberto.

1. Área dos cuidados de saúde e saúde mental é a mais contemplada quando os indivíduos conseguem encaixar-se numa instituição.

2. Área de subsistência básica que pode exigir algum ou alguns destes "subsídios": salário/emprego, reforma, pensão, compensação monetária por ocupação produtiva, alimentação, vestuário, unidade de acolhimento ou residência, etc. Quase sempre alguma destas áreas fica a descoberto a qual impede a inserção ou inclusão.

Há portanto apoios, subsídios, suportes na:

- Área familiar

- Área habitacional

- Área de emprego/salário: (normal ou apoiado com subsídio; ocupações produtivas com compensação monetária de subsistência, etc.).

Por vezes usam-se suportes de inclusão deslocados. Subsídios pessoais numa área quando a carência básica da pessoa é noutra área. Uma percentagem mal estudada dos utentes crónicos (?) das instituições psiquiátricas a desinstitucionalizar (talvez um terço, mas falta investigação), está abaixo do limiar de pobreza e nunca poderão ser inseridos sem remediar essa carência com recursos adequados. O maior erro, que já vem do século XIX, tem sido tentar resolver problemas de extrema pobreza com "subsídios" de cuidados de saúde mental e psiquiatria. Assistem-se muitos a título de doença mental por serem pobres e mendigos. Hoje essa tendência continua para um terço dos chamados doentes mentais.

O tema de pobreza nem sempre aparece em relação à reabilitação psicossocial em saúde mental. Encontra-se, porém, em muita literatura ligada à exclusão social e aos sem-abrigo. E raramente o tema é explicitado na 
sua ligação como obstáculo ao "empowerment" e "recovery". Há aqui como que um tabu devido a certa vergonha de considerar esta realidade. Para realizar o "empowerment" parte-se, é certo, da necessidade de conseguir recursos para residência, subsistência5, despesas correntes, através da formação profissional e do emprego como se toda a população alvo da reabilitação e inclusão pudesse, por golpe de magia, ultrapassar por aí os obstáculos da sua pobreza. Ficam então os recursos psiquiátricos, os ambientes psiquiátricos para colmatar o fosso entre a pobreza do próprio e da família para conseguir o "empowerment" e uma inclusão (?) social contaminada de estigma.

Resultam então as tentativas análogas de resolver a situação:

- Dar, ou dar só, respostas psiquiátricas quando sem subsídios para subsistência básica (pensões, reformas, residência, família, etc.) não resulta em inclusão mas em psiquiatrização continuada.

- Providenciar instituição psiquiátrica em vez de casa familiar ou residência normalizada não é inclusão. É psiquiatrização estigmatizante. Esperamos que este erro não se repita agora mais uma vez e se tente remediar com os projectos de cuidados continuados (em saúde mental).

- Colocar profissionais de saúde para além do regime de SOS para substituir acompanhantes, familiares ou outros da área sócio-familiar, subsidiados quando preciso, vai manter o sujeito dependente e sem inclusão.

- Privilegiar várias terapias substituíveis por actividades produtivas e compensações monetárias torna o sujeito iatrodependente mas não incluído.

Se alguém recebe subsídios ou apoios em 10 ou $20 \%$ do que precisaria para ser independente na sua subsistência numa área, fica dependente desse subsídio, mas não fica com o problema da inclusão resolvido.

5 Cf. José ORNELAS (2008 pp. 262-263) que defende a necessidade de um subsídio de renda para habitação e rendimentos sociais para combater a discriminação das pessoas com doença mental. 
$\mathrm{O}$ mesmo acontece a alguém dependente numa área e o subsidiam ou apoiam noutra em que não precisa, torna-se dependente desse subsídio mas não dá o salto para a inclusão.

\section{Rentabilização dos escalões dos recursos humanos}

Reabilitar e incluir com apoios de pessoas de competências profissionais de salários médios em vez de salários altos torna os projectos mais rentáveis no custo-eficiência-benefício. O recurso ao Gestor da pessoa incapacitada (Case Manager) ou acompanhante dos candidatos à inclusão com competências polivalentes (em saúde mental, gestão e área social) tornaria os projectos de inclusão mais aderentes e próximos das pessoas.

\section{Alguns critérios de avaliação}

A reabilitação/inclusão deve e pode ser sujeita a alguma avaliação. Sugerimos alguns critérios de avaliação do senso comum em forma interrogativa:

- Que número de survivors passaram por programas de reabilitação/ inclusão; quantos passaram períodos consideráveis nas instituições psiquiátricas e a certa altura as dispensaram total ou parcialmente? Se não há, ou há poucos, onde está a inclusão?

- Que grupos de entreajuda foram originados da reabilitação/inclusão?

- Qual o número dos que transitam de situação de maior dependência, exclusão e estigma para maior independência e inclusão?

- Que redução no número de profissionais e de horas de apoio para determinado número de reabilitados/incluídos?

- Que grau de autonomia/independência conseguida após um ano, dois anos...de reabilitação/inclusão em cada projecto?

- Que grau de acréscimo na auto-estima (que faz parte da riqueza do conceito de recovery) para os incluídos e os membros da família? 
- Que níveis de custo-benefício conseguidos com os que já vivem de forma independente e inclusão?

Trata-se apenas de elencar alguns indicadores que permitam avaliar o que se faz. Se não se avalia, ou não se aceita sequer a avaliação, estamos como na psicanálise nunca avaliada, e nem se poderá dizer que há evidências de algo que existe.

\section{Palavras conclusivas}

Não tem muito sentido tirar conclusões do que deixámos escrito em nome de critérios de senso comum. Contudo deixo algumas sugestões.

Podíamos concluir reiterando a necessidade de mais investigação em reabilitação/inclusão. Pensamos que a investigação mais frequente se situa na área clínica mesmo em doentes há longos anos em instituições psiquiátricas. Seria preciso sujeitar estas pessoas a uma investigação metódica de tipo social sobre os seus meios de subsistência (alimentação e vestuário), a família, os recursos de residência, dependência para enfrentar cada uma dessas áreas com apoios específicos. E verificar se com alguns deles a inserção seria possível reduzindo ao mínimo a intervenção técnica psiquiátrica. Outro ponto fundamental diz respeito à necessidade de alguma avaliação e de serem encontrados critérios de avaliação para não se cair em consolação ilusória de mudança mais aparente que real.

Possivelmente verifica-se em muitos casos que não se fazem omeletes sem ovos; e que os recursos não chegam para todos... Na prática é isso que se verifica mais vezes. E como o cobertor é estreito alguns ficam desprotegidos e serão os mais fracos e mais frágeis... e os mais pobres.

Não será que algumas vezes se decretam recursos desafogados para uns, mesmo sabendo que os outros vão ser entregues às instituições do sector social com o desfecho implícito de assim se perpetuarem as razões para considerar esse sector antiquado e merecedor de acantonamentos à margem da equidade económica dos recursos. 


\section{Referências bibliográficas}

ABREU, J. L. PIO (2001). Como tornar-se doente mental, 8. ${ }^{\mathrm{a}}$ ed., Coimbra.

ABREU, M. V. \& SANTOS, E. R. (2007). O papel das famílias e das redes de apoio social, Actas do primeiro Congresso de Reabilitação e inclusão na saúde mental. Coimbra: Almedina Editora.

ARVEILlER, J.-P. \& BONNET, C. (1994). L'insertion du malade mental. Une place pour chacun ou chacun à sa place. Ed. Erés.

BOUBLE, D. (2002). The limits of psychiatry. BMJ, 324 (7432).

BRACKEN, P. \& THOMAS, P. (2001). Post-Psychiatry: a new direction for mental health $B M J$, 322, 724-727. www.bmj.cgi/content/full/322/7288/724.

CARneIro, I. (2000). Reabilitação Psicossocial. Um Processo de Dignificação Humana, (Tese de Mestrado da UCP - Fac. Teologia - Ciências Humanas, Lisboa).

CASA DE SAÚde do TelHal (2006). Tempos e modos, III Jornadas de Reabilitação Psicossocial. CS Telhal.

CORDo, M. (2001). Actividades Produtivas Parte Integrante da Reabilitação Psicossocial, trabalho apresentado no II Seminário de Reabilitação Psicossocial da C.S.S. Miguel (Ponta Delgada) 6 e 7 de Abril.

Reabilitação de pessoas com doença mental, Lisboa 2003.

Gameiro, Aires, O. H. (1989). Manual da Saúde Mental e Psicopatologia. 4. ${ }^{a}$ Ed. Porto: Ed. Salesianas.

(1993). Pastoral e Ética em Psiquiatria. Lisboa: Ed. Hospitalidade.

(1994). Filosofia, Princípios e Técnicas de Reabilitação em Psiquiatria. Utopia ou Mudança de Paradigma? In Reabilitação Recíproca (pp.59-72). Lisboa: Ed. Hospitalidade.

(1999). Carta de Identidade da Ordem Hospitaleira.

(2007). Reabilitação Psicossocial e inclusão na pós-psiquiatria. O estigma de um rótulo discriminatório, seus efeitos, anti-"empowerment" e sua redução. In Abreu, M. V. \& Santos, E. R. (Eds.), O papel das famílias e das redes de apoio social, Actas do primeiro Congresso de Reabilitação e Inclusão na Saúde Mental (pp.63-74). Coimbra: Almedina Editora.

(2002). Factores facilitadores de reabilitação Psicossocial. Uma primeira versão deste trabalho foi apresentado em inglês pelo autor no IX Congresso Internacional da MESPA (Mediterranean Social Psychiatry Association) Barcelona 26 - 30 Maio.

(2002). Times, spaces and occupations as facilitating factors in psychological rehabilitation process (PSR). In II International Congress "Integral Psychosocial Rehabilitation with and within the Community and the IX Congress of MESPA, Barcelona, 28th-30th May.

(2002). Da Ergoterapia à Reabilitação Psicossocial. 8 de Março (Encontro na Casa de Saúde de S. João de Deus, Funchal.

(2006). O Papel do Instituto de S. João de Deus na Psiquiatria em Portugal. In IX Congresso de Psiquiatria S. João de Deus, para uma assistência integrada - inclusão e diversidade, Algueirão, pp.21-30.

O Dr. Luís Cebola e a Casa de Saúde do Telhal (Ordem Hospitaleira de S. João de Deus). Um republicano no Convento. Conferência na Sociedade de Geografia de Lisboa 10.12.2006 (no prelo).

Gameiro, Aires, O. H. et al. Casa de Saúde do Telhal, 1. ${ }^{\circ}$ Centenário 1893-1993.

GAMEIRO, AIRES, O. H. \& FRIAS, S. (1999). Our tailor-made rehabilitation, approach and cases. In 1st North West European Congress on Psychiatric Rehabilitation, Amsterdam, June 6-8. 
(2000). Approches to rehabilitation: in a centre of a peripherical European Union region (Azores). Targets and goals, successes and failures. In VIIth World Congress Psychosocial Rehabilitation: Promoting diversity and ensuring equality, Paris, 7-10 May.

GOFFMAN, E. (1990). Stigma: Notes on the management of Spoiled Identity. London.

Gomes, B. A. (1999). Dos Estabelecimentos de Alienados nos Estados Principais da Europa. Lisboa.

HiPÓlito, M. C. (Coord.) (2007). Saúde Mental, Antologia de Textos para Utentes e Familiares, Lisboa: Federação Nacional das Associações de Famílias Pró Saúde Mental.

HIPÓliTO, M. C. (Coord.) (2007). FNAFSAM, Saúde mental: Posições de EUFAM: Necessidades de cuidadores familiares, medicamentos, tratamento e cuidados, reabilitação e "recovery". FNAFSAM, Lisboa.

Hume, C. \& PUllen, I. (1994). La Riabilitazione dei pazienti psichiatrici. Milano: Raffaello Cortina Editore.

LAM, H. \& RICHARD, M. D. (1998). Desinstitutionalization at the beginning of the new Millenium. Harvard Rev. Psychiatry, May/Jun.

ORgANIZAÇÃo MUNDIAL DE SAÚDE (2009). Integração da Saúde Mental nos cuidados de Saúde primários. Uma perspectiva global. ISBN97892 41563680 [Lisboa].

ORNelas, J. (2008). Psicologia Comunitária. Lisboa: Fim de Século, Lisboa.

Ornelas, J., Monteiro, F. J., Moniz, M. JoÃo VARGas, DuARTE, T. (Coord.) (2005). Participação e Empowerment das Pessoas com Doença Mental e seus Familiares. Lisboa: AEIPS Edições, 2005.

PICHOT, P. \& NATHAN, I. (1998). Quel avenir pour la psychiatrie et la psychoterapie? Le Plessis Robinson.

RODRIgUes, E. V et al. (1999). A Pobreza e a Exclusão Social: Teorias, Conceitos e Políticas... ler.letras.up.pt/ uploads/ ficheiros/1468.pdf (15.12.09)

S/A (2005). Livro Verde, Melhorar a saúde mental da população, Rumo a uma estratégia de saúde mental para a União Europeia. Bruxelas.

SARTORIUS, N. (2002). Iatrogenic Stigma of Mental Illness. BMJ, 324, 1471. (www.com/cgi/ content/full/324/7352/1470)

SIMON, H. (1937). Tratamiento ocupacional de los enfermos mentales. Barcelona.

WALKER, M. T. (2006). The Social Construction of Mental Illness and its Implications for the Recovery Model. International Journal of Psychosocial Rehabilitation, 10 (1), 71-87. www.cmhawrb.on.ca/stigma.htm, Stigma and Mental health 